Modern Physics Letters A, Vol. 14, No. 40 (1999) 2813

(C) World Scientific Publishing Company

\title{
ERRATA
}

\section{PAIR PRODUCTION IN A TIME-DEPENDENT MAGNETIC FIELD}

\author{
[Mod. Phys. Lett. A, Vol. 14, No. 18 (1999) 1183-1192]
}

GIORGIO CALUCCI

On p. 1187, sixth line of Eq. (13) should read:

$$
T_{6}=\langle-, n+1|M|-, n\rangle=\sqrt{2} k b e^{-i \theta} \sqrt{n+1}\left[\left(w_{-, n}+m\right)\left(w_{-, n+1}+m\right)\right]^{-1} .
$$

On p. 1188, the first line of Eq. (15) should read:

$$
\mathcal{J}=\frac{1}{2 e n \dot{B}}\left[f\left(S_{0}\right) \sqrt{2 e n B_{0}+k^{2}}+f(S(t)) \sqrt{2 e n B(t)+k^{2}}\right] .
$$

On p. 1191, the sentence (fifth line from top)

"A more formal and ... is therefore impossible." is wrong and must be taken away. 